pain, a sugar pill can be as effective in some people as an opioid analgesic.

This latest picture may explain why different people have varied responses to pain and injury. For example, Thernstrom witnesses Hindu pilgrims piercing their cheeks and tongues with metal skewers in a sacred ritual, apparently without feeling pain. It also hints at why nontraditional approaches, such as hypnotism, can be successful in treating pain. Yet despite this wider understanding, the treatment of chronic pain remains woefully inadequate.

Anyone experiencing what Thernstrom calls the "misunderstood, misdiagnosed and undertreated disease" of chronic pain will be familiar with her years of bafflement, pointless expense on treatments that don't work, and consultations with physicians who don't understand. (I am among those whose pain did not go away, after a disc herniation three years ago; only in the past few months did I stumble across a specialist who could explain why my pain persists.) Treatment is improving, but, even now, there is roughly only one pain specialist for every 25,000 patients in the United States. Meanwhile, chronic pain costs the country more than US $\$ 100$ billion a year.

Thernstrom argues that the problem is mainly one of disseminating new understanding. I disagree. Although she focuses on recent studies, the idea that pain can result from a damaged nervous system is not new. Many of the core concepts were laid out by psychologists Ronald Melzack and Patrick Wall in their 1982 book The Challenge of Pain (Penguin).

Anaesthetics were not widely used to treat pain until a century after their discovery because cultural preconceptions - for instance, about the virtue of suffering - needed to be overcome first. A similar shift in attitudes is necessary for medicine to properly embrace the science of pain. The belief that pain should be borne as an unavoidable fact of life persists among some physicians. For many others, the possibility of curing a life-threatening disease probably holds more appeal than showing patients how to manage a non-threatening but incurable one.

Regardless of what sustains the divide between the lab and the clinic, The Pain Chronicles should narrow it. I hope that Thernstrom's industrious survey of the latest research, treatment biases and patient and physician perspectives will prompt some health-care givers to rethink their approach. And patients who read her book will no longer have to remain in the dark or feel so alone. Thernstrom's descriptions of what it is like to live with "a broken alarm that rings continuously, signaling only its own brokenness" give a voice to millions of people whose lives are blackened by something that no one else can see.

Lucy Odling-Smee is an Opinion editor at Nature.

\title{
An embellished tale of Pluto's discovery
}

\section{Percival's Planet: A Novel \\ by Michael Byers \\ Henry Holt: 2010.432 pp. $\$ 27$}

Eighty years ago, the hunt for a mysterious Planet X culminated in the discovery of Pluto. Lying beyond Neptune in the Solar System, the orb was named after the Greek god of the underworld and became part of our family of nine planets. In 2006, having completed just one-third of an orbit around the Sun since its detection, Pluto was declared a mere 'dwarf planet', an interloper from deep space, and was cast out of that family.

Percival's Planet is novelist Michael Byers's fictionalized history of the discovery. Interweaving real people and events with imagined ones in a pastiche of the United States in the late 1920s, he tells the (real) tale of Planet X an unseen planet at the Solar System's edge that had been predicted by wealthy businessmanturned-astronomer Percival Lowell to explain anomalies in the orbits of Neptune and Uranus. Into the search for the putative planet steps Clyde Tombaugh, working at the Lowell Observatory in Flagstaff, Arizona, which Lowell had endowed. After Tombaugh's efforts pay off, Planet $\mathrm{X}$ is renamed Pluto by a schoolgirl who wins a competition.

Tombaugh's story of serendipity frames the novel. A farmer's son from Kansas, he was a skilled technician and a self-taught maker of telescopes. In the novel, he shares the stage with a bewildering array of characters, from Harvard astronomers to fading boxers, confused heirs and beautiful women, both sane and insane. All these actors orbit ever closer to the Lowell Observatory, perturbing each other more and more until they collide. Byers's portrayal of the United States on the cusp of the Great Depression is meticulous; glimpses of

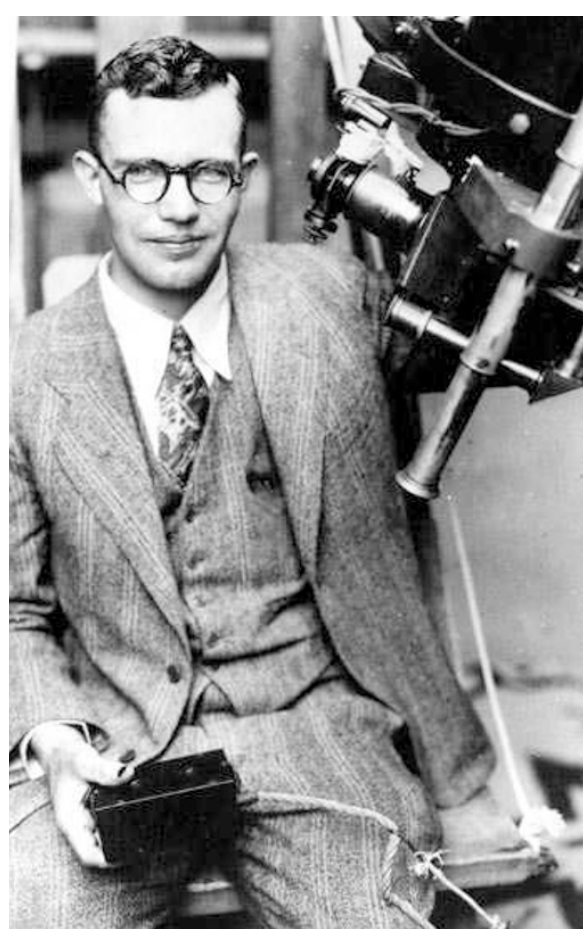

Clyde Tombaugh rose from humble origins to discover Pluto. inner dialogue and period details help build an immersive world.

The true story of Pluto's discovery is here, but it is slow to come to the fore. And the mix of fact and fiction can be unsettling. Fabricated characters crucial to the story coexist with real people such as Tombaugh, his fellow astronomer Vesto Slipher and Lowell's widow. Many readers will find themselves turning to Google for information about what is true and what is not.

Byers's choice of embellishment over historic accuracy is understandable because the search for Planet X involved countless hours of drudgery: meticulous astronomical observation, long periods staring at photographic plates and uneventful book keeping. In real life, cool discoveries are often made by normal people who then just go home and have tea. By adding flesh and blood to the true story of Pluto, Byers reinvigorates its history.

Like witnessing men walking on the Moon 40 years later, finding Pluto was a milestone in the lives of a generation. It came at a pivotal moment when human horizons expanded. The discovery coincided with the birth of modern cosmology, when the vast scale of the Universe was revealed, and when improved global communications meant that a crash on Wall Street reverberated around the world. Science was changing too, becoming more professional. Yet the pace of investigation remained genteel: researchers could take their time on speculative projects such as the hunt for Planet X. This wider context makes Byers's imagined tale of 
real science more compelling.

Percival's Planet ends before Tombaugh's death, a graceful effort to avoid Pluto's miserable - albeit scientifically justified demotion. But there is a neat coda to the tale.
Some of Tombaugh's ashes are now on board the New Horizons mission to that distant, frigid dwarf planet. Speeding through the outer planets, his ashes will arrive in 2015 at the speck caught by his sharp eye a lifetime ago.
Not bad for a farmer's boy from Kansas. Caleb Scharf is director of astrobiology at Columbia University, New York 10027, USA, and author of Extrasolar Planets and Astrobiology. e-mail: caleb@astro.columbia.edu

\section{Behind the Mona Lisa's smile}

\section{X-ray scans reveal Leonardo's remarkable control of glaze thickness, explains Philip Ball.}

Leonardo da Vinci was renowned as a prevaricating genius, apt to undertake too much, to experiment open-endedly and to stall over details. "This man will never do anything!", Pope Leo X is said to have complained after finding the artist concocting a new kind of varnish rather than beginning a commissioned work. Even Leonardo's Mona Lisa portrait was never formally completed, although he laboured on it for four years beginning in 1503 , and returned to it many times throughout his life.

A study of the Mona Lisa's paint layers, published in Angewandte Chemie International Edition last month (L. de Viguerie et al. Angew. Chem. Int. Ed. doi:10.1002/anie.201001116; 2010), gives insight into the techniques over which Leonardo obsessed. Philippe Walter and his colleagues at the Centre for Research and Restoration of French Museums - based, like the painting, in the Louvre in Paris - found that the smooth shading of the iconic face is a product of astonishingly fine control of glaze thickness, and that Leonardo experimented widely with painting methods and materials on other portraits.

Rather than extract paint samples from the sacrosanct flesh tones of the Mona Lisa's face, Walter and colleagues exploited a non-invasive technique that has only recently been applied to art analysis: X-ray fluorescence spectroscopy. Bombardment of the material with $\mathrm{X}$-rays excites an electronic transition from an atom's inner shell. The excited electron then decays by emitting another X-ray, the energy of which reveals the atom's elemental identity. Thanks to improvements in instrumentation and in software - developed when the team worked with other artworks using the bright $\mathrm{X}$-ray source at the European Synchrotron Radiation Facility in Grenoble, France - the technique can now be used on site to map out elements horizontally across the paint surface and vertically through the layers.

The researchers have traced how the composition and thickness of the layers varies from light to shadow on the face of the Mona Lisa, and in the flesh tones of six other paintings by Leonardo in the Louvre. Walter and his team were

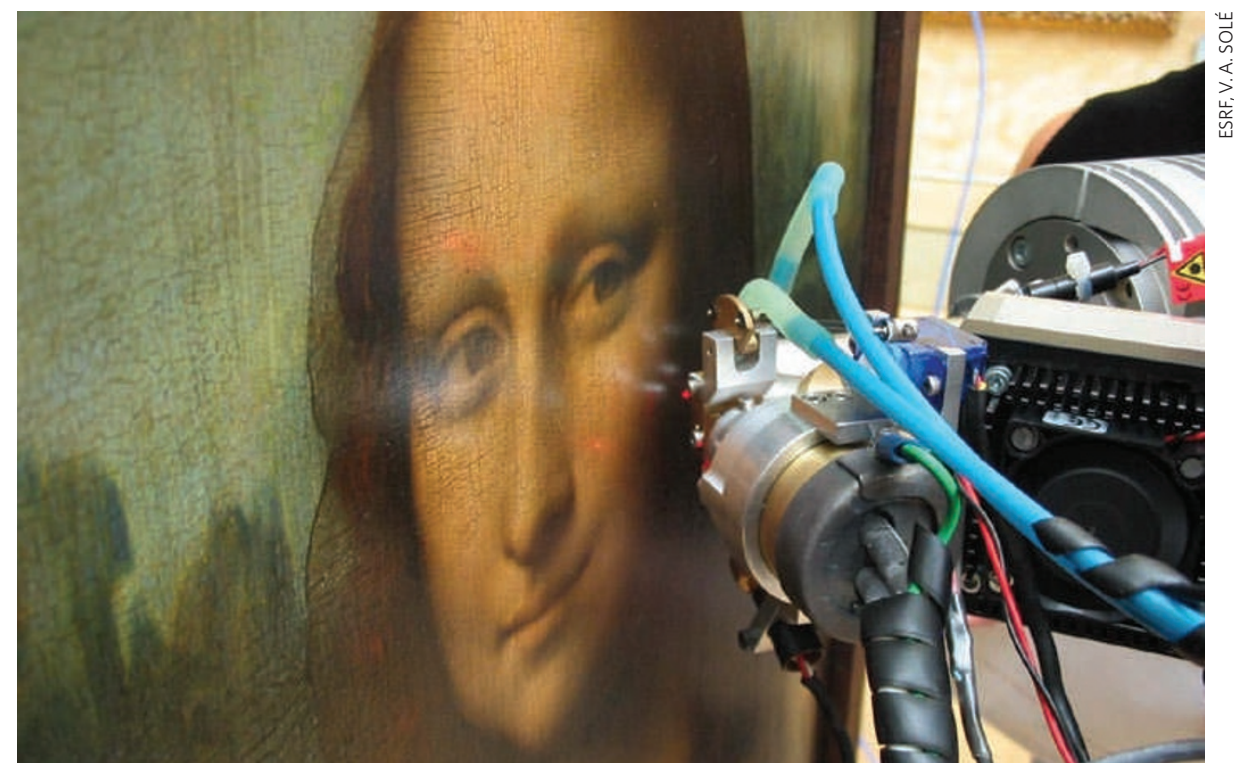

Rare artworks can be analysed on site using X-ray spectroscopy - without removing paint samples.

particularly keen to establish how Leonardo achieved his trademark sfumato ('smoky') shading, which is devoid of evident brush marks.

It was known that this style exploits a glazing technique developed by fifteenth-century northern European oil painters such as Jan van Eyck, in which a translucent paint is laid over an opaque one. But the details of how Leonardo used it to such great effect were obscure. Walter et al. find that the thickness of a brown glaze placed over the pink base of the Mona Lisa's cheek grades smoothly from just 2-5 micrometres to around 30 micrometres in the deepest shadow, and that it is made up of an iron-oxide earth pigment darkened with manganese oxide. Although these materials were widely used, Leonardo's control of glaze thickness is remarkable. He probably used his fingertips, as van Eyck did, rather than a brush.

This finding confirms Leonardo as an innovative artist. He trained in the studio of Andrea del Verrocchio in Florence, but was apparently ready to abandon the pigment-mixing method preferred by Florentine artists in favour of experiments with glazing, similar to those conducted in Venice after the northern European painting techniques reached Italy.

That enthusiasm for experimentation is confirmed by analyses of the other Leonardo paintings, in which he used a variety of materials and techniques, including direct mixing, in the flesh tones. It also tallies with his reputed interest in chemistry, which seemingly provoked Pope Leo's impatience at his tinkering and distilling. It is possible that analyses of other Leonardo paintings might allow his experimental methods to act as chronological markers - a valuable goal, given that the current dating of his works is sketchy.

Prospects for further analyses of the Louvre's paintings on site are challenged by the decision of France's culture ministry to relocate Walter's research laboratories to the town of Neuvillesur-Oise in Cergy-Pontoise, some 30 kilometres outside Paris. The new centre, which is scheduled to operate from 2013, will house conservation laboratories and accommodate 250,000 artworks now stored in the Louvre and other Parisian museums. But the upheaval is taking its toll on staff morale, casting a shadow over the future of scientific research at the Louvre. Philip Ball is a writer based in London. 